\title{
Net Analyte Signal Standard Additions Method for Simultaneous Determination of Sulfamethoxazole and Trimethoprim in Pharmaceutical Formulations and Biological Fluids
}

\author{
M. H. GIVIANRAD ${ }^{*}$ and M. MOHAGHEGHIAN \\ Department of Chemistry, Science and Research Branch, \\ Islamic Azad University, Tehran, Iran \\ givianradh@yahoo.com
}

Received 22 August 2011; Accepted 27 October 2011

\begin{abstract}
The applicability of a novel net analyte signal standard addition method (NASSAM) to the resolving of overlapping spectra corresponding to the sulfamethoxazole and trimethoprim was verified by UV-visible spectrophotometry. The results confirmed that the net analyte signal standard additions method with simultaneous addition of both analytes is suitable for the simultaneous determination of sulfamethoxazole and trimethoprim in aqueous media. Moreover, applying the net analyte signal standard additions method revealed that the two drugs could be determined simultaneously with the concentration ratios of sulfamethoxazole to trimethoprim varying from 1:35 to $60: 1$ in the mixed samples. In addition, the limits of detections were 0.26 and $0.23 \mu \mathrm{mol} \mathrm{L}{ }^{-1}$ for sulfamethoxazole and trimethoprim, respectively. The proposed method has been effectively applied to the simultaneous determination of sulfamethoxazole and trimethoprim in some synthetic, pharmaceutical formulation and biological fluid samples.
\end{abstract}

Keywords: Sulfamethoxazole, Trimethoprim, NASSAM, Biological Fluids, Pharmaceutical formulations.

\section{Introduction}

Sulfamethoxazole (4-amino- $N$-(5-methylisoxazol-3-yl)-benzenesulfonamide) and trim-ethoprim (5-(3,4,5- trimethoxybenzyl) pyrimidine- 2,4- diamine) (Figure $1 \mathrm{~A}$ and B) occur in a 5:1 (w/w) mixture as co-trimoxazole in a number of dosage forms, including tablets, oral suspension, and human or veterinary intravenous infusion medicine. This synergism combination is widely used for the treatment of a variety of infections caused by Gram-positive and Gram-negative bacteria such as urinary and respiratory tract infections ${ }^{1}$. Sulfamethoxazole SMX) inhibits bacterial (synthesis of dihydrofolic acid by competing with paraaminobenzoic acid. Trimethoprim (TMP) blocks the production of tetrahydrofolic acid from dihydrofolic acid by binding to and reversibly inhibiting the required enzyme, dihydrofolate reductase ${ }^{2}$. 
Various methods have been reported for determination of SMX and TMP in pharmaceutical formulations and biological fluids ${ }^{3-14}$. Most of these methods use a separation method such as high-performance liquid chromatography (HPLC) $)^{3-8}$ or capillary electrophoresis ${ }^{9}$. The USP monograph $^{15}$ lists a high-performance liquid chromatographic method as the official assay procedure for quality control. The British pharmacopoeia ${ }^{16}$ suggests a sequential method based on extraction by an organic solvent. However, these methods are expensive and time-consuming. Besides these methods, UV-Visible spectrophotometry can be used as a rapid, sensitive and inexpensive analytical tool. However, the lack of specificity of the UV-Visible absorption spectrophotometry and the problem due to spectral overlap in determination of SMX and TMP made the use of chemometric techniques inevitable ${ }^{10-14}$. Chemometrics such as multicomponent derivative spectroscopic analysis ${ }^{10}$, ratio spectra derivative spectrometry ${ }^{11}$, Principal Component Regression (PCR) analysis ${ }^{12}$ and bivariate calibration spectrophotometric method ${ }^{13}$ and ratio derivative spectrophotometry with simultaneous standard additions ${ }^{14}$ have been used for simultaneous determination of SMX and TMP.

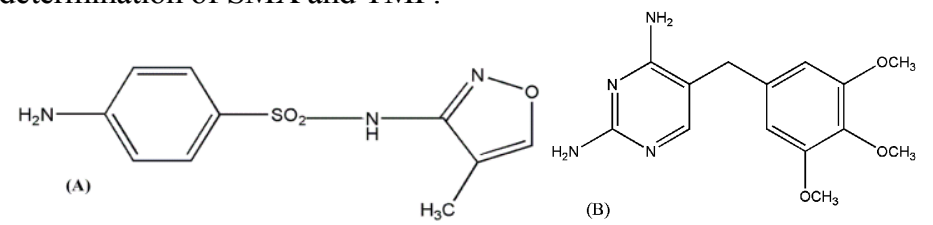

Figure 1. Structural formula of Sulfamethoxazole (A) and Trimethoprim (B).

In this work, a sensitive, selective, accurate and inexpensive procedure was applied for simultaneous spectrophotometric determination of SMX and TMP by using the net analyte signal standard additions method (NASSAM) with simultaneous addition of both analytes. This method is a novel standard addition method based on the net analyte signal (NAS) concept. In this paper, an attempt was made to calculate NAS vectors and attribute them to the analyte concentration using UV-visible spectrophotometry technique. However, this method was evaluated with the recommended British Pharmacopoeia method for some pharmaceutical productions.

The net analyte signal (NAS) was defined by Lorber ${ }^{17}$, based on spectroscopic methods, as the part of the spectrum of a mixture that is unique for the analyte of interest, i.e., it is orthogonal to the spectra of the interferences.

The conventional notation has been employed throughout the subsequent discussion. Boldface capital letter is used for a matrix, a boldface lower case for a column vector and lightface lower case italic for a scalar. The superscript $\mathrm{T}$ designates the operation of the vector or matrix transposition and the superscript + indicates the pseudo-inverse of a nonsquare matrix. The digitized spectrum is referred to as a spectrum vector or simply as a vector, while a spectrum vector of a pure component is called a component vector.

Consider a synthetic mixture containing SMX $\left(10 \mu \mathrm{mol} \mathrm{L}^{-1}\right)$ and TMP $\left(20 \mu \mathrm{mol} \mathrm{L} \mathrm{L}^{-1}\right)$. The simultaneous determination of two analytes by NASSAM requires having spectrum vector of the mixture. The known amounts of both SMX and TMP are successively added to the sample solution. The resulting absorbances are measured and expressed by the following equations:

$$
\begin{gathered}
A_{0}=\varepsilon_{S M X} C_{S M X}^{0}+\varepsilon_{T M P} C_{T M P}^{0} \\
A_{1}=A_{0}+\varepsilon_{S M X} C_{S M X, s_{1}}+\varepsilon_{T M P} C_{T M P, s_{1}} \\
A_{i}=A_{i-1}+\varepsilon_{S M X} C_{S M X, s_{i}}+\varepsilon_{T M P} C_{T M P, s_{i}} \\
A_{n}=A_{n-1}+\varepsilon_{S M X} C_{S M X, s_{n}}+\varepsilon_{T M P} C_{T M P, s_{n}}
\end{gathered}
$$


where $\mathrm{A}_{0}$ and $\mathrm{A}_{\mathrm{i}}$ are the absorbances of the synthetic mixture before and after of standard additions. $C_{S M X}^{0}, C_{T M P}^{0}$ and $C_{S M X, s_{i}}, C_{T M P, s_{i}}$ are the initial concentrations of SMX and TMP and added concentrations to the sample in the $\mathrm{i}^{\text {th }}$ step. Also $\varepsilon_{S M X}$ and $\varepsilon_{T M P}$ are molar absorptivities of SMX and TMP, respectively.

The NAS of SMX and TMP compounds, $\mathrm{NAS}_{\mathrm{SMXi}}$ and $\mathrm{NAS}_{\mathrm{TMPi}}$ can be found by the following equations, respectively:

$$
\begin{aligned}
N A S_{S M X_{i}} & =\left(I-T^{+} T\right) A_{i} \\
N A S_{T M P_{i}} & =\left(I-S^{+} S\right) A_{i}
\end{aligned}
$$

where "I" is an identical matrix, "T" and "S" are the matrix of absorbances in different concentrations of SMX and TMP, respectively. By definition, it is always possible to split up the spectrum of a sample $\left(\mathrm{A}_{\mathrm{i}}\right)$ into two distinct parts: $\mathrm{NAS}_{\mathrm{SMX}}$, which is orthogonal to the spectra of the interferences and $T^{+} T A_{i}$ where $T^{+} T A_{i}$ is the part of the spectrum that could was generated by a linear combination of the spectra of the interfering agents. Consequently, $T^{+} T A_{i}$ cannot be unique for the analyte of interest, because it can also be produced by a mixture of interfering agent. Furthermore, NAS $_{\mathrm{SMX}}$ is orthogonal to the spectra of the interferences reflecting the part of the spectrum, which is only depending on the analyte SMX present in the mixture. A Similar expression can be used for TMP. Therefore, the orthogonal vectors of SMX and TMP which known as NAS $\mathrm{SMX}_{\mathrm{S}}$ and NAS $\mathrm{SMP}_{\mathrm{TMP}}$ can be used for quantification of the analytes SMX and TMP, respectively ${ }^{17-19}$. Figure 2 shows the geometrical presentation of analyte, interferent, mixtures, $T^{+} T A_{i}$ and NASSMX vectors. The shape of NASSMX only depends on the presence of interferences in the mixture, not on their specific concentrations and only addition or deletion of components can change NASSMX. In the following, it is assumed that spectra of samples without the analyte are available and are remained constant during the determination.

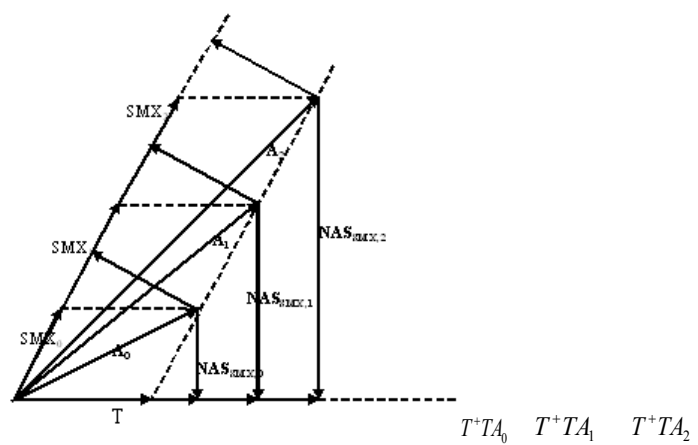

Figure 2. Representation in two dimensional vector space analyte (SMX) and vector space another analyte (TMP). NAS vector NAS $\mathrm{SMX}_{\mathrm{S}}$ will be different from SMX in direction and length.

In binary and/or ternary mixtures when the interferences are known, the NAS can be calculated for the analytes. Norm of the NAS vector can be used to construct a univariate calibration model, where this parameter is plotted against the analyte concentration and a 
linear relationship is observed. In the case of matrix effect, standard addition plots can be constructed against added standard additions.

\section{Experimental}

To demonstrate the analytical applicability of the proposed method for the analysis of binary mixtures, two pure spectra of SMX and TMP were recorded separately. As it is shown in Figure 3, the spectra are too overlapped in the range of 220-320 $\mathrm{nm}$. Figure 4 shows successive standard addition of two analytes (SMX and TMP) in a certain ratio into binary mixture. NAS curves for components were calculated simultaneously based on Eqs. $(5,6)$ and demonstrated in Figure $5 \mathrm{~A}$ and B, respectively. Figure $6 \mathrm{~A}$ and $\mathrm{B}$ shows the norms of NAS vectors for analytes (SMX and TMP) versus standard concentrations that could be used to calculate the simultaneous concentrations of SMX and TMP from intercept, respectively.

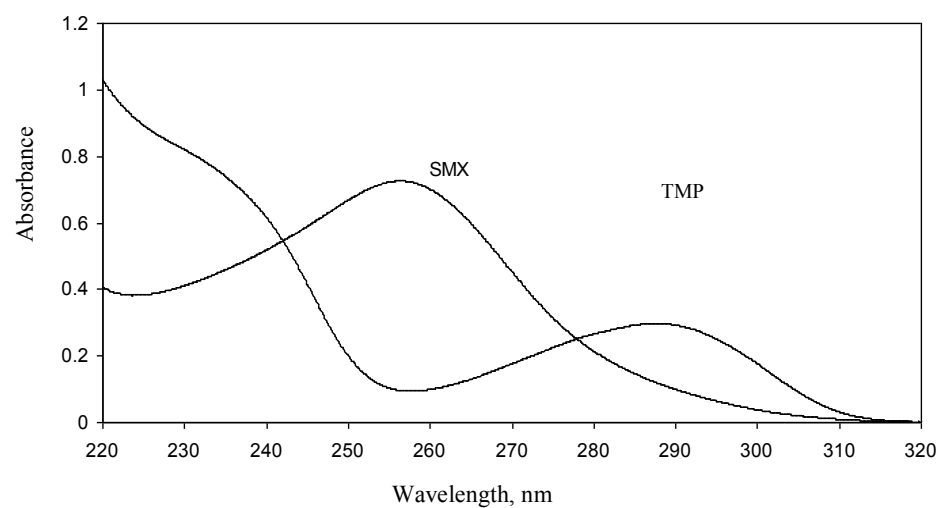

Figure 3. Absorption spectra of (a) $40 \mu \mathrm{mol} \mathrm{L} \mathrm{L}^{-1}$ sulfamethoxazole (b) $40 \mu \mathrm{mol} \mathrm{L} \mathrm{L}^{-1}$ trimethoprim $\mathrm{pH} 10.0$.

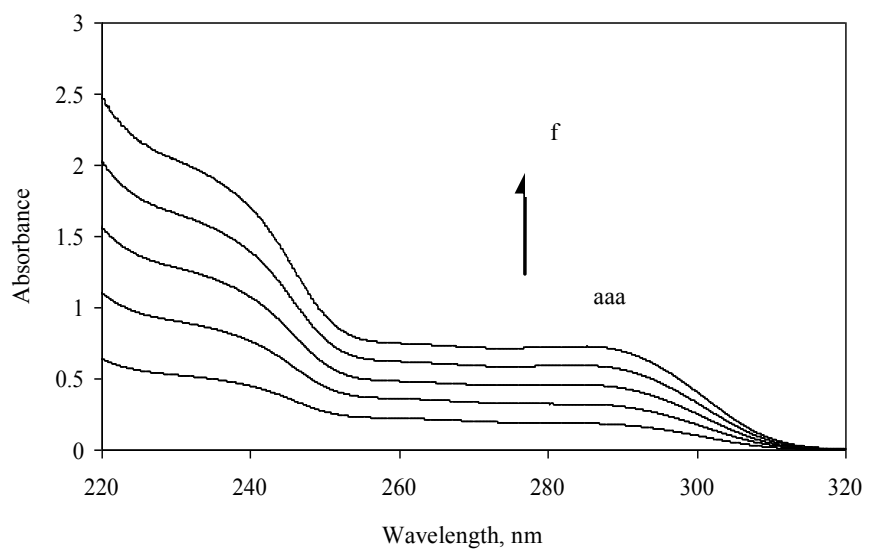

Figure 4. Absorption spectra of binary mixtures of SMX $\left(10 \mu \mathrm{mol} \mathrm{L}{ }^{-1}\right)$ and TMP $\left(20 \mu \mathrm{mol} \mathrm{L}^{-1}\right)$ after addition of $0,5,10,15$ and $20 \mu \mathrm{mol} \mathrm{L}^{-1} \mathrm{SMX}$ and $0,15,30,45$ and $60 \mu \mathrm{mol} \mathrm{L}{ }^{-1} \mathrm{TMP}$ (a-f) at $\mathrm{pH} 10.0$. 

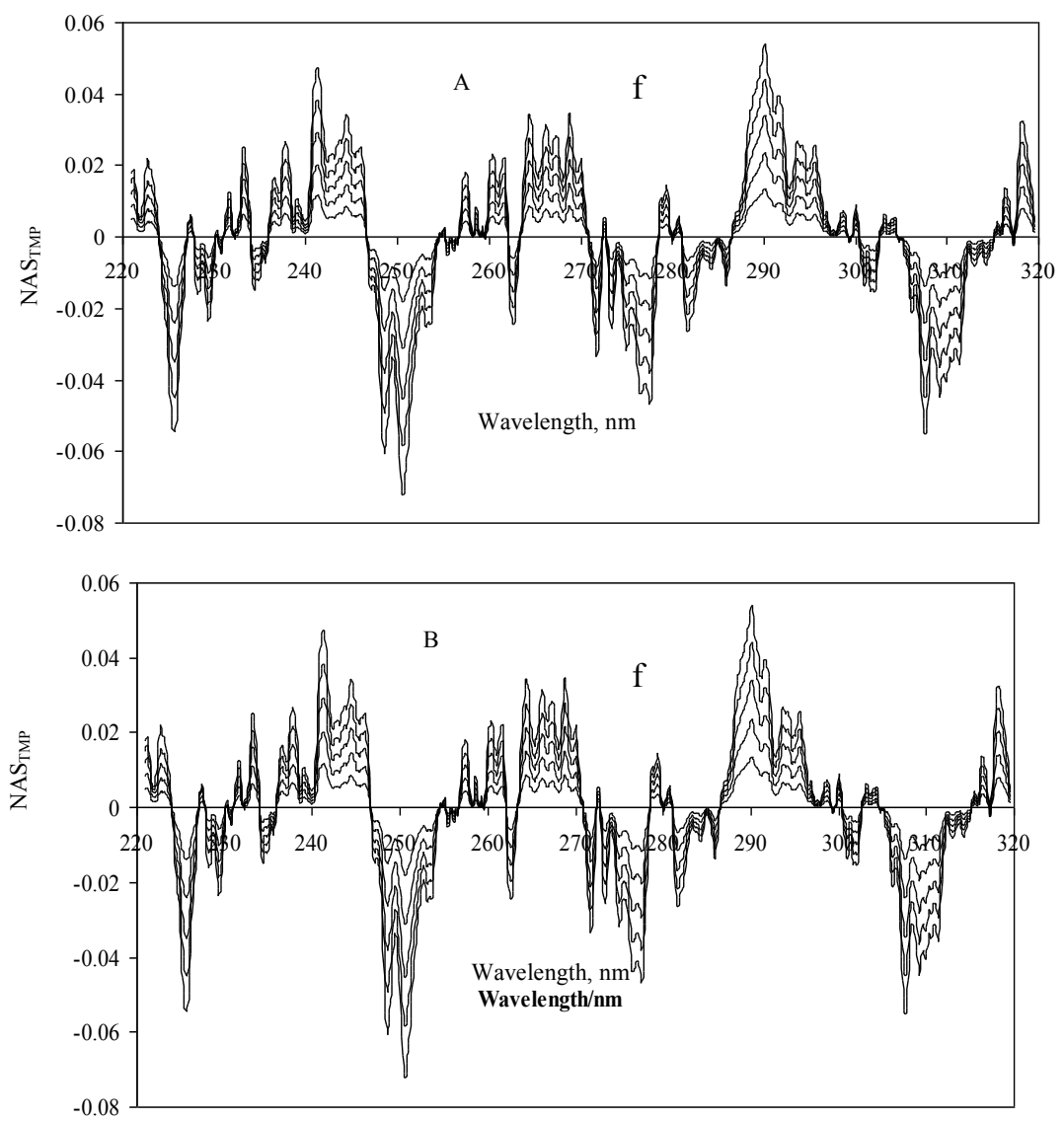

Figure 5. (A) $\mathrm{NAS}_{\mathrm{SMX}}$ and (B) $\mathrm{NAS}_{\mathrm{TMP}}$ spectra of binary mixtures of SMX $\left(10 \mu \mathrm{mol} \mathrm{L} \mathrm{L}^{-1}\right)$ and TMP $\left(20 \mu \mathrm{mol} \mathrm{L}^{-1}\right)$ after addition of $0,5,10,15$ and $20 \mu \mathrm{mol} \mathrm{L} \mathrm{L}^{-1} \mathrm{SMX}(\mathrm{a}-\mathrm{f})$ and $0,15,30$, 45 and $60 \mu \mathrm{mol} \mathrm{L}^{-1}$ TMP (a-f) at $\mathrm{pH} 10.0$.

\section{Reagents}

SMX (Virchow Laboratories, Hyderabad, India, 99.78\%) and TMP (Inventaa Laboratories, Hyderabad, Andhra Pradesh, India, 99.4\%) were kindly provided by Tehran Darou Co. (Tehran, Iran). Analytical grade phosphoric acid, boric acid, acetic acid, sodium hydroxide and chloroform were purchased from E. Merck (Darmstadt, Germany). All other reagents were of analytical grade. Nanopure water system with specific resistivity of $18.3{\mathrm{M} \Omega \mathrm{cm}^{-1}}^{-1}$ (Millipore) was used for all solutions.

Britton-Robinson (B-R) buffers $\left(0.1 \mathrm{~mol} \mathrm{~L}^{-1}\right.$ in phosphate, acetate and borate) in the $\mathrm{pH}$ range of 2-12 were used throughout. A $1.0 \times 10^{-3} \mathrm{~mol} \mathrm{~L}^{-1} \mathrm{SMX}$ solution was prepared daily by dissolving $0.2538 \mathrm{~g} \mathrm{SMX}$ in $1.0 \times 10^{-3} \mathrm{~mol} \mathrm{~L}^{-1}$ sodium hydroxide solution and was diluted with the same solution in a $1000 \mathrm{~mL}$ volumetric flask to the mark. A $1.0 \times 10^{-3} \mathrm{~mol} \mathrm{~L}^{-1} \mathrm{TMP}$ solution was prepared daily by dissolving $0.2920 \mathrm{~g}$ of TMP in water and diluted in a $1000 \mathrm{~mL}$ volumetric flask. These solutions were reserved in a refrigerator at $4{ }^{\circ} \mathrm{C}$ in dark. More dilute solutions were prepared by serial dilution with water. 

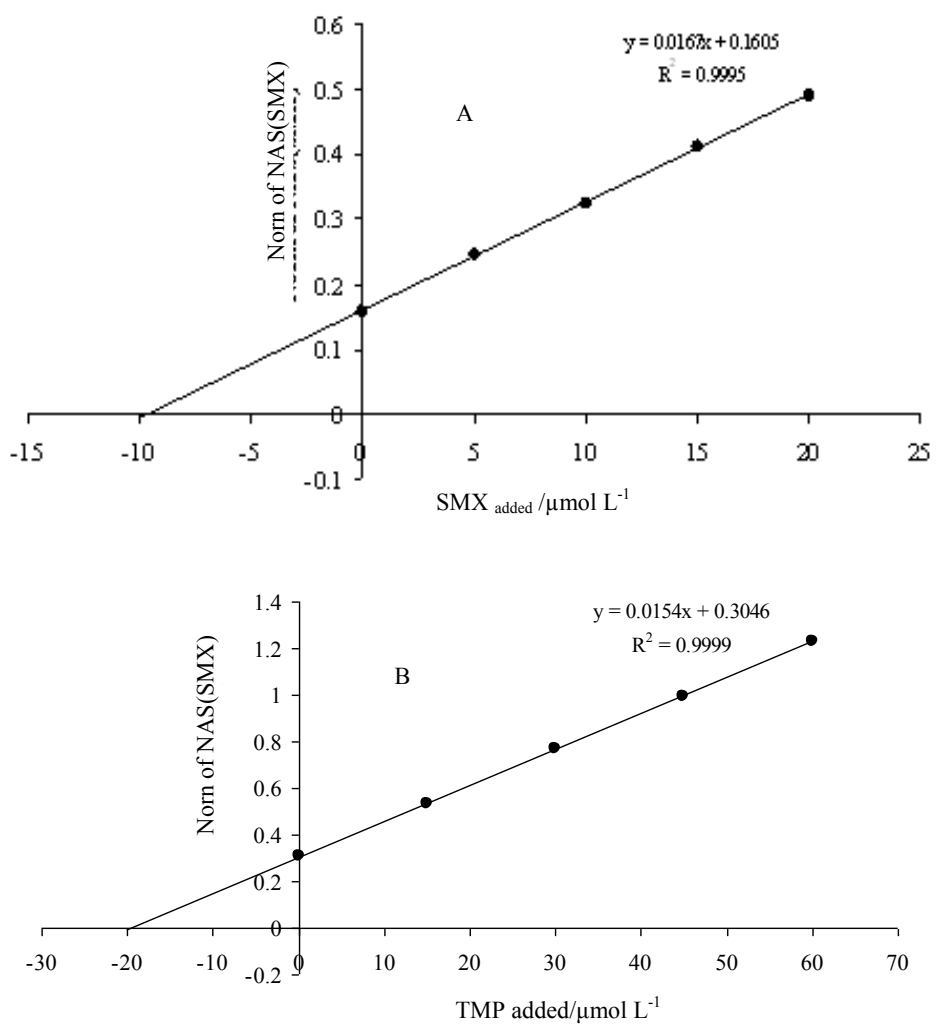

Figure 6. Plot of Norms of $\mathrm{NAS}_{\mathrm{SMX}}(\mathrm{A})$ and (B) NAS $\mathrm{NMP}_{\mathrm{TM}}$ vs. added concentration for binary mixtures of SMX $\left(10 \mu \mathrm{mol} \mathrm{L}^{-1}\right)$ and TMP $\left(20 \mu \mathrm{mol} \mathrm{L}^{-1}\right)$ at $\mathrm{pH} 10.0$.

\section{Instrumentation and software}

UV-Visible absorption spectra were measured on an Agilent UV-Vis spectrophotometer, PerkinElmer (Lambda 25), with the use of $1.0 \mathrm{~cm}$ quartz cells. A Pentium IV $(2.53 \mathrm{GHz})$ computer controlled all the setting and data processing. All spectra were saved in text files and transformed to an in house Matlab program version 7.6.0.324 (R2008a) to calculate the norm of NAS vectors. A pH-meter (Metrohm, Model 827) with a double junction glass electrode was used to verify the $\mathrm{pH}$ of the solutions. A potentiometer (Horiba, Model M-12) with a calomel reference electrode and a Pt indicator electrode was utilized to measure SMX according to British pharmacopoeia method.

\section{Preparation of real samples}

Drug samples of Co-trimoxazole involves pediatric Co-trimoxazole oral suspension containing $200 \mathrm{mg}$ SMX and $40 \mathrm{mg}$ TMP in each $5 \mathrm{~mL}$ drug, pediatric Co-trimoxazole tablet containing $100 \mathrm{mg}$ SMX and $20 \mathrm{mg}$ TMP in each tablet, adult Co-trimoxazole tablet containing $400 \mathrm{mg}$ SMX and $80 \mathrm{mg}$ TMP in each tablet, forte Co-trimoxazole tablet containing $800 \mathrm{mg}$ SMX and $160 \mathrm{mg}$ TMP in each tablet produced by Tehran Darou Co.(Tehran-Iran), Co-trimoxazole human intravenous infusion sample containing $400 \mathrm{mg}$ SMX and $80 \mathrm{mg}$ TMP in each ampoule $(5 \mathrm{~mL})$ produced by Caspian Tamin pharmaceutical Co.(Rasht-Iran) and Co-trimoxazole veterinary intravenous infusion sample containing $200 \mathrm{mg} \mathrm{SMX}$ and 
$40 \mathrm{mg}$ in each $1 \mathrm{~mL}$ solution produced by Kela Co.(Belgium), were used as real samples of pharmaceutical formulations. For tablet samples, 20 tablets were weighed and powdered, and then a quantity of powder containing $100 \mathrm{mg}$ sulfamethoxazole and $20 \mathrm{mg}$ trimethoprim was dissolved in $1.0 \times 10^{-3} \mathrm{~mol} \mathrm{~L}^{-1}$ sodium hydroxide solution and was diluted with the same solution in a $1000 \mathrm{~mL}$ volumetric flask to the mark. For human intravenous infusion samples, 20 ampoules were mixed and a quantity of drug containing $100 \mathrm{mg}$ sulfamethoxazole and $20 \mathrm{mg}$ trimethoprim was dissolved in water and diluted in a $1000 \mathrm{~mL}$ volumetric flask to the mark. For veterinary intravenous infusion samples, a quantity of drug containing $100 \mathrm{mg}$ sulfamethoxazole and $20 \mathrm{mg}$ trimethoprim was dissolved in water and diluted in a $1000 \mathrm{~mL}$ volumetric flask to the mark. More dilute solutions were prepared by serial dilution with water. However, the quantities of two drugs, which were mentioned by producer companies, were considered as approximate quantities.

Human serum and plasma samples were obtained and stored frozen until the assay. Into each of 6 centrifugation tubes containing a certain concentration of SMX and/or TMP, $1.0 \mathrm{~mL}$ of the human serum or plasma sample was transferred and then mixed well with $10.0 \mathrm{~mL}$ of methanol to precipitate the blood proteins. The precipitated proteins were separated by centrifuging of the mixture for $20 \mathrm{~min}$ at $4000 \mathrm{rpm}$. The clear supernatant layer was filtered through a $0.45 \mu \mathrm{m}$ milli-pore filter to produce protein-free human serum or plasma. The human serum or plasma samples were transferred into a $25 \mathrm{~mL}$ calibrated flask adding $2 \mathrm{~mL}$ solution of B-R buffer of $\mathrm{pH} \mathrm{10}$, diluted to the volume with water and then was introduced to the optical cell.

\section{British pharmacopoeia method}

The British pharmacopoeia method as a standard method for determination of SMX and TMP in Co-trimoxazole drugs was compared with NASSAM results. According to this procedure for tablet samples, 20 tablets were weighed and powdered. For determination of SMX, a quantity of powder containing $0.5 \mathrm{~g}$ of SMX was dissolved in $60 \mathrm{~mL}$ water and $10 \mathrm{~mL}$ of Conc. hydrochloric acid and 3 g potassium bromide was added to the sample solution. Then, after cooling the solution in ice, the sample solution was slowly titrated with $0.1 \mathrm{M}$ sodium nitrite by stirring constantly and the end point was determined potentiometrically. For determination of TMP, to a quantity of powder containing $50 \mathrm{mg}$ of TMP, $30 \mathrm{~mL}$ of $0.1 \mathrm{M}$ sodium hydroxide was added and extracted with four $50 \mathrm{~mL}$ quantities of chloroform and washed each extract with the same $10 \mathrm{~mL}$ quantities of $0.1 \mathrm{M}$ sodium hydroxide. Then the chloroform extracts were combined and extracted with four $50 \mathrm{~mL}$ quantities of $1 \mathrm{M}$ acetic acid, then the combined extracts were washed with $5 \mathrm{~mL}$ of chloroform and the aqueous extracts were diluted to $250 \mathrm{~mL}$ with $1 \mathrm{M}$ acetic acid. Finally, $10 \mathrm{~mL}$ of the solution, $10 \mathrm{~mL}$ of $1 \mathrm{M}$ acetic acid and sufficient water were added to produce solution in a $100 \mathrm{~mL}$ volumetric flask and the absorbance of the resulting solution at the maximum of $271 \mathrm{~nm}$ was measured spectrophotometrically. For determination of SMX and TMP in intravenous infusion Co-trimoxazole drugs and TMP in Co-trimoxazole oral suspension, a similar procedure like the above-mentioned procedure was applied. However, for determination of SMX in oral suspension drugs, $5 \mathrm{~mL}$ of the oral suspension was added to $30 \mathrm{~mL}$ of $0.1 \mathrm{M}$ sodium hydroxide, shaken and extracted with four $50 \mathrm{~mL}$ quantities of chloroform, washing each extract with the same two $10 \mathrm{~mL}$ quantities of $0.1 \mathrm{M}$ sodium hydroxide. The aqueous solution and washings were combined and diluted to $250 \mathrm{~mL}$ with water, then filtered and $5 \mathrm{~mL}$ of the filtrate was diluted to $200 \mathrm{~mL}$ with water. Afterward, $0.5 \mathrm{~mL}$ of $4 \mathrm{M}$ hydrochloric acid and $1 \mathrm{~mL}$ of a $0.1 \% \mathrm{w} / \mathrm{v}$ solution of sodium nitrite was added to the $2 \mathrm{~mL}$ of above solution, by protecting from light. Then, after 2 minutes $1 \mathrm{~mL}$ of a $0.5 \% \mathrm{w} / \mathrm{v}$ solution of ammonium sulphamate was added and allowed to stand for 3 minutes, subsequently $1 \mathrm{~mL}$ of a $0.1 \% \mathrm{w} / \mathrm{v}$ solution of $N$-(1-naphthyl) ethylenediamine dihydrochloride was added and 
allowed to stand for 10 minutes. The resulting solution was diluted to $25 \mathrm{~mL}$ with water and consequently, the absorbance was measured at $538 \mathrm{~nm}$.

\section{Recommended procedure}

According to the mentioned theoretical section, two standard solution series of SMX and TMP in $25 \mathrm{~mL}$ volumetric flasks containing $2 \mathrm{~mL}$ Britton-Robinson buffer solution (pH 10.0) were prepared from 1-80 $\mu \mathrm{mol}$ with $1.0 \mu \mathrm{mol}$ increments. Subsequently, the absorbance spectra of each series solution were accomplished at appropriate wavelength range $(220-320 \mathrm{~nm})$ with $0.1 \mathrm{~nm}$ increments. Then, the absorbance spectra of each series stored in separate text files as T.txt and S.txt, respectively. As already declared, "S" and "T" are the matrices of the absorbance in different concentrations of SMX and TMP, respectively. Thus, this part of job was accomplished just for one time, which could be used for prospective endeavors.

For sample assay, an aliquot of the solution containing SMX and/or TMP and $2 \mathrm{~mL}$ Britton-Robinson buffer solution ( $\mathrm{pH} 10.0$ ) were added into a $25 \mathrm{~mL}$ volumetric flask and made up to the mark with water. After that, a certain portion of the solution was transferred into a quartz cell to measure its absorbance at appropriate wavelength range (220-320 nm) with $0.1 \mathrm{~nm}$ increments. Then, after each standard addition of both components, the spectra were saved as text files (A.txt). For calculating the norms of SMX, A.txt and T.txt files and for calculating the norms of TMP, A.txt and S.txt files were transferred to Matlab program, respectively. Consequently, the concentration of each component was calculated by standard addition plot.

\section{Results and Discussion}

The absorption spectra of SMX and TMP under certain experimental conditions are shown in Figure 3. As can be seen, the maximum wavelengths of two compounds are close to each other and their spectra overlap. Therefore, determination of SMX and TMP in the presence of each other is impractical by classical spectrophotometry. Therefore, the NASSAM was used as a chemometrics method to solve matrix effect and interferent errors, simultaneously.

\section{Effect of operational parameters}

In order to optimize the procedure for the simultaneous determination of SMX and TMP, the effect of $\mathrm{pH}$ and scan wavelength range was studied. As it is shown in Figure $7 \mathrm{~A}$ and $\mathrm{B}$, the absorbance at maximum wavelength does not change significantly, but the overlap between two species is reduced by increasing of $\mathrm{pH}$. Consequently, $\mathrm{pH}$ of 10 was selected as an optimum to obtain higher selectivity. Also the spectra wavelength range was studied in different ranges according to Table 1 , the best result for recovery and accuracy for determination of SMX and TMP by the proposed method was obtained in the range of 220$320 \mathrm{~nm}$. Table 2, shows results for simultaneous determination of SMX and TMP in some synthetic mixtures. As it is seen, the two drugs could be determined simultaneously with acceptable recovery for the concentration ratios of sulfamethoxazole to trimethoprim varying from 1:35 to $60: 1$ in the mixed samples.

\section{Reproducibility}

In order to study the reproducibility of the proposed method, some synthetic mixtures containing SMX and TMP have been analyzed several times $(n=6)^{20,21}$. The results were shown in Table 3 with their confidence intervals. The means of the calculated RSD (\%) were 1.92 and 2.14 for SMX and TMP, respectively. 
688 M. H. GIVIANRAD et al.
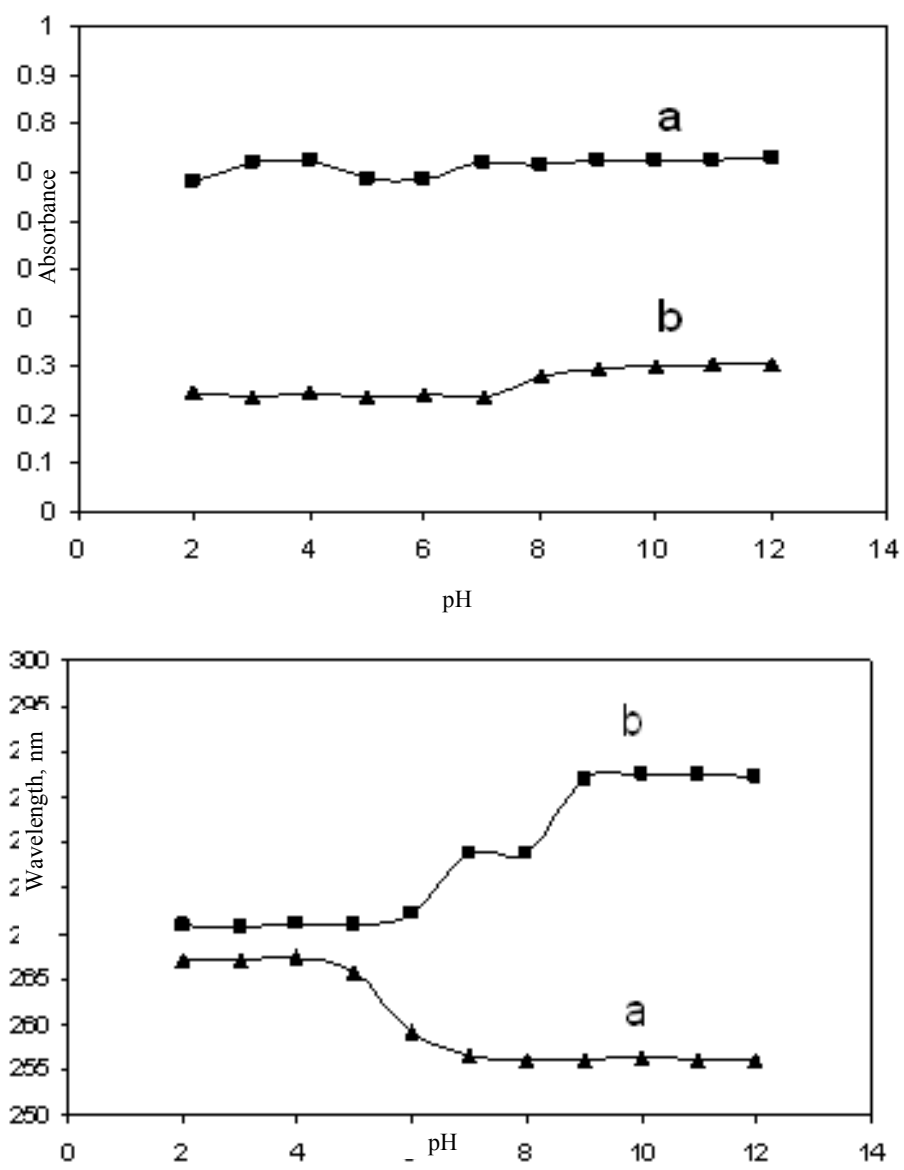

Figure 7. (A) Effect of $\mathrm{pH}$ on the maximum absorption spectra of sulfamethoxazole (a) and trimethoprim (b). (B) Effect of $\mathrm{pH}$ on the $\lambda_{\max }$ of sulfamethoxazole (a) and trimethoprim (b). Conditions: $40 \mu \mathrm{mol} \mathrm{L}^{-1}$ sulfamethoxazole and $40 \mu \mathrm{mol} \mathrm{L}^{-1}$ trimethoprim.

Table 1. Effect of scan wavelength range on the recovery of proposed method for $40 \mu \mathrm{mol} \mathrm{L} \mathrm{L}^{-1}$ of SMX and $40 \mu \mathrm{mol} \mathrm{L}^{-1} \mathrm{TMP}$ solution.

\begin{tabular}{ccccc}
\hline \multicolumn{2}{c}{ Recovery, $\%$} & \multicolumn{2}{c}{ Found $/ \mu \mathrm{mol} \mathrm{L}$} & \\
\cline { 1 - 3 } TMP & SMX & TMP & SMX & Wavelength Range, nm \\
\hline 91.62 & 100.80 & 36.65 & 40.32 & $200-320$ \\
99.68 & 100.00 & 39.87 & 40.00 & $220-320$ \\
99.00 & 99.85 & 39.60 & 39.94 & $240-320$ \\
98.68 & 99.72 & 39.47 & 39.89 & $260-320$ \\
98.20 & 100.13 & 39.28 & 40.05 & $280-320$ \\
95.00 & 145.00 & 38.00 & 58.00 & $300-320$ \\
\hline
\end{tabular}


Table 2. Determination of SMX and TMP in some synthetic mixtures.

\begin{tabular}{cccccc}
\hline \multicolumn{2}{c}{ Recovery, $\%$} & \multicolumn{2}{c}{ Found $/ \mu \mathrm{mol} \mathrm{L}^{-1}$} & \multicolumn{2}{c}{ Present in the sample/ $\mu \mathrm{mol} \mathrm{L}^{-1}$} \\
\hline TMP & SMX & TMP & SMX & TMP & SMX \\
\hline 101.60 & 103.20 & 5.08 & 5.16 & 5 & 5 \\
101.30 & 107.00 & 40.52 & 5.35 & 40 & 5 \\
102.50 & 112.00 & 92.25 & 5.60 & 90 & 5 \\
99.68 & 100.00 & 39.87 & 40.00 & 40 & 40 \\
100.00 & 100.18 & 5.00 & 80.15 & 5 & 80 \\
100.62 & 105.50 & 70.44 & 2.11 & 70 & 2 \\
105.83 & 119.00 & 63.50 & 1.19 & 60 & 1 \\
112.50 & 101.74 & 2.25 & 71.22 & 2 & 70 \\
107.00 & 102.36 & 1.07 & 51.18 & 1 & 50 \\
1 & 60 & 1.06 & 55.25 & & \\
\hline
\end{tabular}

Table 3. Results of the replicate measurements for determination of SMX and TMP in synthetic mixtures, expressed as $\bar{X} \pm(\mathrm{tS} . \mathrm{D}.) / \sqrt{N}$, for $\mathrm{N}=6$ measurements and $\mathrm{t}(\mathrm{N}-1=5)$ $=2.571$.

\begin{tabular}{|c|c|c|c|c|c|}
\hline \multicolumn{2}{|c|}{$\begin{array}{l}\text { Present in the sample } \\
\qquad / \mu \mathrm{mol} \mathrm{L} \mathrm{L}^{-1}\end{array}$} & \multicolumn{2}{|c|}{ Found $/ \mu \mathrm{mol} \mathrm{L} \mathrm{L}^{-1}$} & \multicolumn{2}{|c|}{ RSD, \% } \\
\hline SMX & TMP & SMX & TMP & SMX & TMP \\
\hline 5 & 5 & $5.18 \pm 0.06$ & $5.16 \pm 0.11$ & 1.20 & 2.09 \\
\hline 5 & 40 & $5.46 \pm 0.10$ & $40.15 \pm 0.65$ & 1.83 & 1.61 \\
\hline 5 & 90 & $5.88 \pm 0.26$ & $91.09 \pm 2.55$ & 4.25 & 2.66 \\
\hline 40 & 40 & $40.04 \pm 0.36$ & $40.92 \pm 0.67$ & 0.87 & 1.56 \\
\hline 80 & 5 & $80.22 \pm 1.22$ & $5.18 \pm 0.15$ & 1.45 & 2.81 \\
\hline
\end{tabular}

\section{Sensitivity}

Sensitivity was studied by means of the limit of detection (LOD), defined as follows ${ }^{22-24}$ $\mathrm{LOD}=3 s_{b}$, Where $s_{b}$ is the standard deviation of several $(n=6)$ replicated measurements of zero concentration of analyte with the NASSAM. The corresponding values obtained were 0.26 and $0.23 \mu \mathrm{mol} \mathrm{L}{ }^{-1}$ for SMX and TMP, respectively.

\section{Interferents}

The influence of several ions and some molecules were experienced on the absorbance of the appropriate wavelengths, including those that most frequently would be accompanied with SMX and TMP in real samples. The effect of potential interfering species at different concentrations on the absorbance of a solution containing $10 \mu \mathrm{mol} \mathrm{L}^{-1}$ SMX and $10 \mu \mathrm{mol} \mathrm{L}^{-1} \mathrm{TMP}$ was studied. The tolerance limit was defined as the concentration, which gives an error of $\leq 10 \%$ in the determination of species. The effect of all examined interferents was given in Table 4, at several molar ratios over SMX and TMP on the measured analytical signal. From the results, it is concluded that the method is comparatively selective for determination of two analytes. 
Table 4. Maximum tolerance concentrations of some species for determination of SMX and TMP.

\begin{tabular}{lc}
\hline Species & Tolerance concentration $/ \mu \mathrm{mol} \mathrm{L}$ \\
\hline $\mathrm{Na}^{-1}, \mathrm{~K}^{+}, \mathrm{Mg}^{2+}, \mathrm{Ca}^{2+}, \mathrm{Cu}^{2+}, \mathrm{Co}^{2+}, \mathrm{Ag}^{+}, \mathrm{Cd}^{2+}$, & \\
$\mathrm{Fe}^{2+}, \mathrm{Mn}^{2+}, \mathrm{Zn}^{2+}, \mathrm{Bi}^{3+}, \mathrm{Cr}^{3+}, \mathrm{Al}^{3+}, \mathrm{Fe}^{3+}, \mathrm{NO}_{3}^{-}, \mathrm{Cl}^{-}$, & 10000 \\
$\mathrm{I}^{-}, \mathrm{Br}^{-}, \mathrm{CHCOO}, \mathrm{PO}_{4}{ }^{3-}, \mathrm{SO}_{4}^{2-}, \mathrm{C}_{2} \mathrm{H}_{5} \mathrm{OH}$ & 100 \\
Folic acid, Glucose, Sodium benzoate, Vitamin & \\
C, Vitamin $\mathrm{B}_{1}$ & \\
\hline
\end{tabular}

\section{Determination of SMX and TMP in some real samples}

Applicability of the proposed method was demonstrated by simultaneous determination of SMX and TMP in some pharmaceutical formulations and biological fluid. The results for the analysis of pharmaceutical formulations were compared with the British pharmacopoeia method. As it is shown in Table 5, a good agreement was observed between the proposed method and standard method. In addition, as it is shown in Table 6, the proposed method was tested in some biological fluids (human serum and plasma) and the results were validated with spiked standard solutions with superior consistency.

Table 5. Results of the replicate measurements for determination of SMX and TMP in some pharmaceutical formulations, expressed as $\bar{X} \pm$ (tS.D.) $/ \sqrt{N}$, for $\mathrm{N}=6$ measurements and $\mathrm{t}_{(\mathrm{N}-1=5)}=2.571$.

\begin{tabular}{lcccccc}
\hline & \multicolumn{2}{c}{$\begin{array}{c}\text { Approximate } \\
\text { doses, mg }\end{array}$} & $\begin{array}{c}\text { Found(mg) by British } \\
\text { pharmacopoeia }\end{array}$ & \multicolumn{2}{c}{$\begin{array}{c}\text { Found(mg) by } \\
\text { NASSAM }\end{array}$} \\
\cline { 2 - 7 } & SMX & TMP & SMX & TMP & SMX & TMP \\
\hline $\begin{array}{l}\text { Co-trimoxazole } \\
\text { adult tablet }\end{array}$ & 400 & 80 & $400.75 \pm 0.57$ & $72.61 \pm 0.45$ & $399.10 \pm 7.21$ & $81.52 \pm 2.83$ \\
$\begin{array}{l}\text { Co-trimoxazole } \\
\text { forte tablet }\end{array}$ & 800 & 160 & $807.77 \pm 28.56$ & $149.88 \pm 1.5$ & $815.53 \pm 9.33$ & $170.54 \pm 4.28$ \\
$\begin{array}{l}\text { Co-trimoxazole } \\
\text { pediatric tablet }\end{array}$ & 100 & 20 & $103.89 \pm 2.98$ & $19.41 \pm 1.31$ & $101.97 \pm 0.71$ & $20.65 \pm 0.46$ \\
$\begin{array}{l}\text { Co-trimoxazole } \\
\text { oral Suspension }\end{array}$ & 200 & 40 & $206.08 \pm 0.27$ & $38.59 \pm 0.10$ & $206.29 \pm 3.44$ & $39.67 \pm 0.41$ \\
$\begin{array}{l}\text { Co-trimoxazole } \\
\text { veterinary } \\
\text { intravenous infusion }\end{array}$ & 200 & 40 & $199.73 \pm 0.45$ & $36.77 \pm 0.40$ & $205.30 \pm 2.46$ & $41.91 \pm 0.88$ \\
$\begin{array}{l}\text { Co-trimoxazole } \\
\text { human intravenous } \\
\text { infusion }\end{array}$ & 400 & 80 & $424.71 \pm 1.79$ & $74.29 \pm 1.29$ & $408.69 \pm 2.86$ & $83.51 \pm 0.97$ \\
\hline
\end{tabular}


Table 6. Results of the replicate measurements for determination of SMX and TMP in some biological fluids, expressed as $\bar{X} \pm(t S . D.) / \sqrt{N}$ for $\mathrm{N}=6$ measurements and $t_{(\mathrm{N}-1=5)}=2.571$.

\begin{tabular}{ccccccc}
\hline Sample & \multicolumn{2}{c}{ Added, $\mu$ mol L } & \multicolumn{2}{c}{ Found, $\mu$ mol L } & \multicolumn{2}{c}{ Recovery, \% } \\
\cline { 2 - 7 } & SMX & TMP & SMX & TMP & SMX & TMP \\
\hline \multirow{3}{*}{ Plasma } & 10 & 10 & $10.18 \pm 0.13$ & $10.88 \pm 0.16$ & 101.8 & 108.8 \\
& 30 & 20 & $30.27 \pm 0.53$ & $20.78 \pm 0.23$ & 100.9 & 103.9 \\
& 50 & 30 & $50.95 \pm 0.57$ & $31.12 \pm 0.86$ & 101.9 & 103.7 \\
Serum & 20 & 20 & $20.12 \pm 0.26$ & $20.62 \pm 0.44$ & 100.6 & 103.1 \\
& 30 & 40 & $30.41 \pm 0.39$ & $41.08 \pm 0.72$ & 101.4 & 102.7 \\
& 50 & 30 & $50.51 \pm 0.48$ & $30.67 \pm 0.33$ & 101.2 & 102.2 \\
\hline
\end{tabular}

\section{Conclusion}

Quantification of sulfamethoxazole and trimethoprim was accomplished from spectrophotometric data by a novel method based on the net analyte signal and standard addition of two analytes in a certain ratio. The recommended method would be having both feature of standard addition and also net analyte signal methods. Furthermore, the analyte concentrations can be determined simultaneously. In this study, a factor analysis method that does not require factor selection was developed. In comparison with two popular multivariate calibration methods, i.e., PCR and PLS, which require that the optimum number of factors or principal components are selected. The proposed method does not need wavelength selection and it is useful for simultaneous determination of analytes in mixtures without the need for a prior separation or special conditions to resolve the analytes spectra. The proposed method is simple, inexpensive, precise and affordable; it also requires no complex pretreatment. Hence, it is recommended for use in routine analysis of mixtures of drugs giving spectra overlapping.

\section{Acknowledgment}

The authors appreciatively acknowledge the support of this work by Islamic Azad University branch of Gachsaran (IAUG). In addition, the assistance of Tehran Darou Co. for offering pure drugs is gratefully acknowledged.

\section{References}

1. Goodman and Gilman, The Pharmaceutical Basis of Therapeutics, New York, 1980, 1116-1119.

2. Patel R B and Welling P G, Clin Pharmacokinet., 1980, 5, 405-423.

3. Vander S K and Sonneveld P, J Chromatogr., 1987, 422, 328-333.

4. Spreux-Varoguax O, Chapalain J P, Cordonnier P, Adveuier C, Pays M and Lamine L, J Chromatogr, 1983, 274, 187-199.

5. DeAngelis DV, Woolley J L and Sigel C W, Ther Drug Monit., 1990, 12, 382-392.

6. Laizur S C, Holden C L and Stevens R C, J Chromatogr, 1990, 528, 235-242.

7. Amini H and Ahmadiani A, J Pharm Biomed Anal., 2007, 43, 1146-1150.

8. Mistri H N, Jangid A G, Pudage A, Shah A and Shrivastav P S, Microchem J, 2010, 94, 130-138.

9. Qing-Cui C, Xiu-Hui T, Lian-Mei J, Wen-Jun Z and Jian-Nong Y, Chin J Anal Chem., 2008, 36, 292-296.

10. Othman S, Int J Pharmaceut., 1990, 63, 173-176.

11. Berzas Nevado J J, Lemus Gallego J and Castanedu Penalvo G, Fresenius J Anal Chem., 1992, 342, 723-728. 
12. Ribone M E, Pagani A P, Goicoechea H C and Olivieri A C, Chem Educador., 2000, 5, 236-241.

13. Lopez-Martinez L, Lopez-de-Alba P L, de-Leon-Rodriguez L M and Yepez-Murrieta M L, J Pharm Biomed Anal., 2002, 30, 77-85.

14. Hajian R, Haghighi R and Shams N, Asian J Chem., 2010, 8, 6569-6579.

15. United State Pharmacopeia 32, National Formulary 272009.

16. British Pharmacopoeia, Volume III, 2009.

17. Lorber A, Anal Chem., 1986, 58, 1167-1172.

18. Lorber A, Farber K and Kawalski B R, Anal Chem., 1997, 69, 1620-1628.

19. Farber N M, Anal Chem., 1998, 70, 5108-5110.

20. Saber-Tehrani M, Hashemi-Moghaddam H, Givianrad M H and Abroomand-Azar P, Anal Bioanal Chem., 2006, 386, 1407-1412.

21. Saber-Tehrani M, Givianrad M H and Kahkashan P, Bio Trace Elem Res., 2007, 116, 155-169.

22. Givianrad M H, Saber-Tehrani M, Abroomand-Azar P and Mohagheghian M, Spectrochim Acta., 2011, 78, 1196-1200.

23. Saber-Tehrani M, Givianrad M H, Hashemi-Moghaddam H, Talanta., 2007, 71, 1319-1325.

24. Ganjavi M, Ezzatpanah H, Givianrad M H and Shams A, Food Chem., 2010, 118, 525-528. 


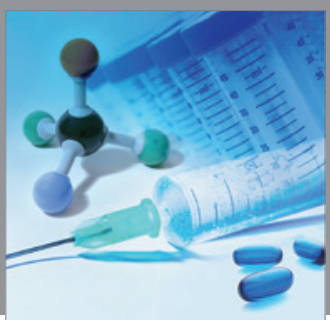

International Journal of

Medicinal Chemistry

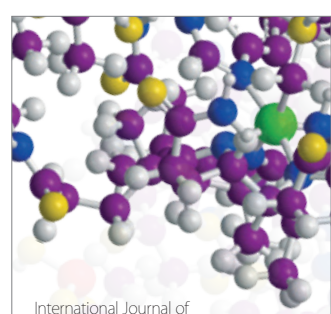

Carbohydrate Chemistry

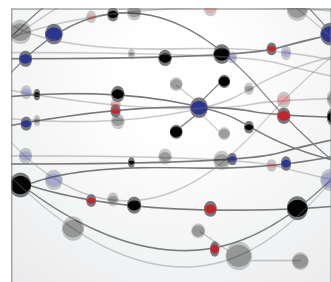

The Scientific World Journal
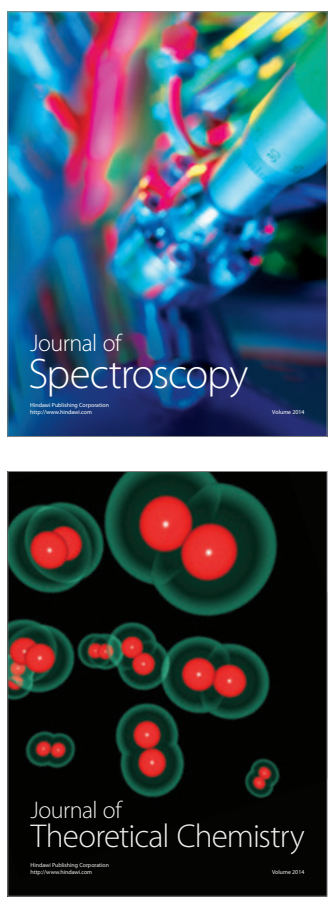
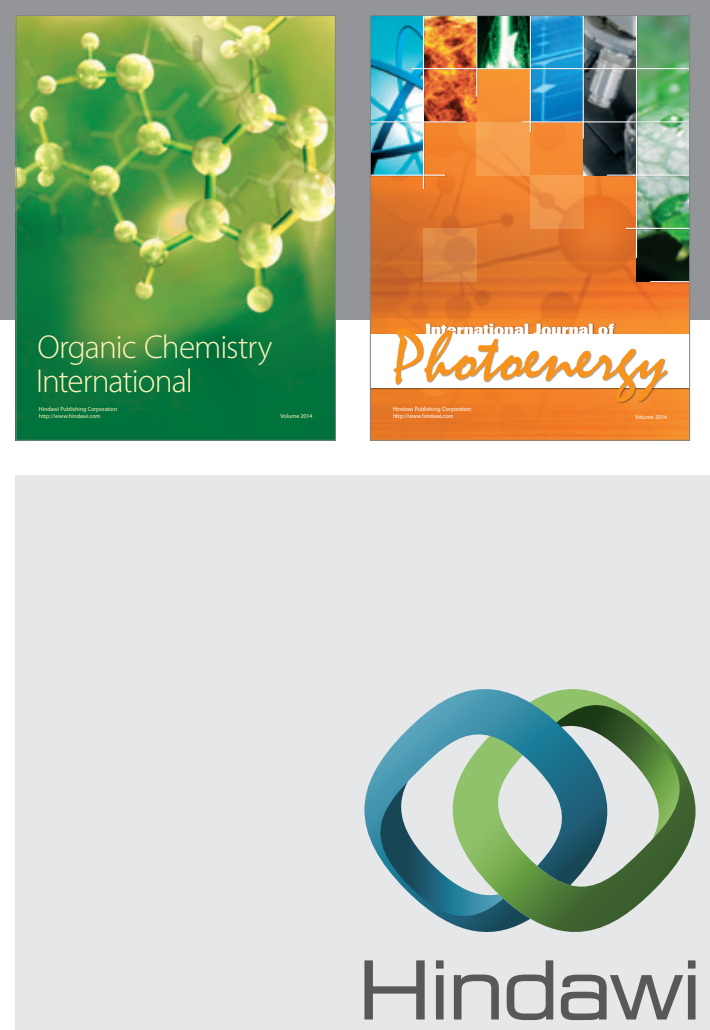

Submit your manuscripts at

http://www.hindawi.com
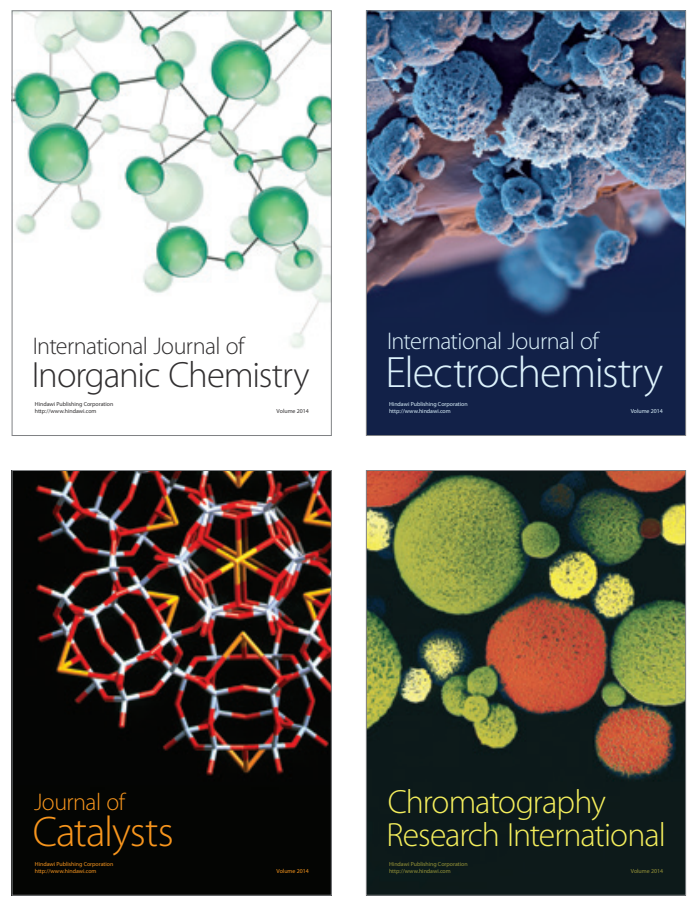
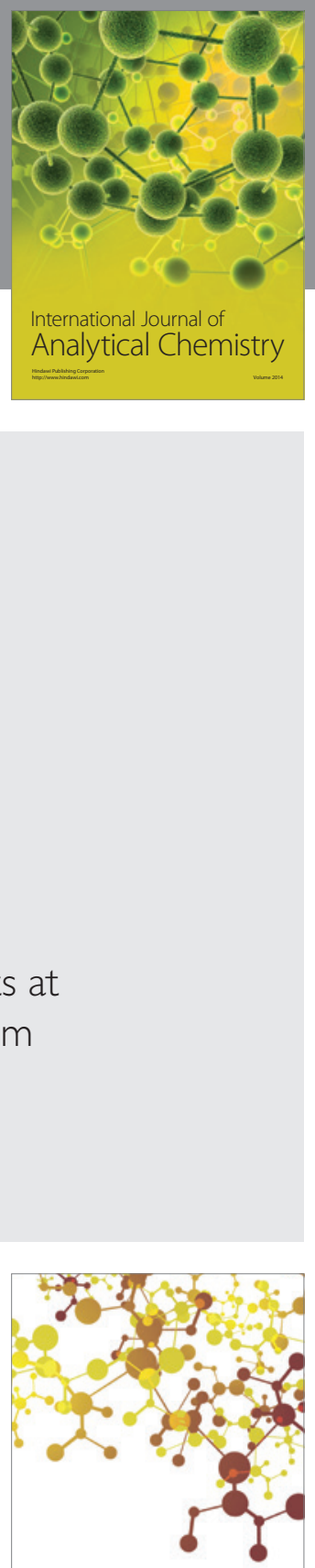

Journal of

Applied Chemistry
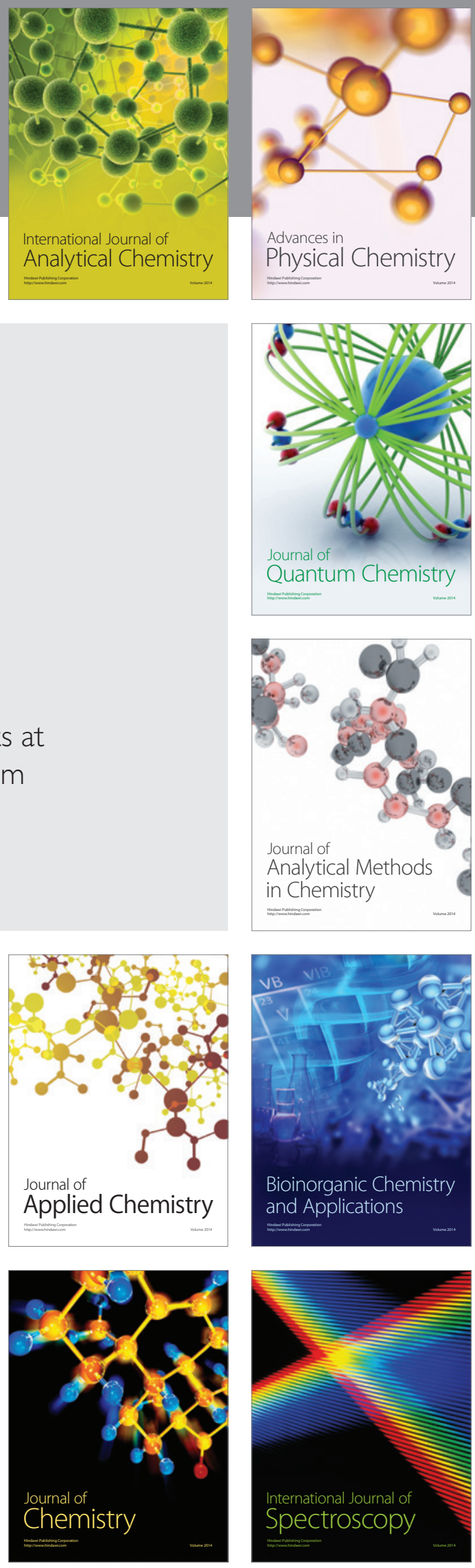